\title{
Tracing Cardiac Metabolism In Vivo: One Substrate at a Time
}

\author{
Heinrich Taegtmeyer \\ Division of Cardiology, Department of Internal Medicine, the University of Texas Medical School at Houston, Houston, Texas
}

\begin{abstract}
In the myocardial cell, a series of enzyme-catalyzed reactions results in the efficient transfer of chemical energy into mechanical energy. The goals of this article are to emphasize the ability of noninvasive imaging techniques using isotopic tracers to detect the metabolic footprints of heart disease and to propose that cardiac metabolic imaging is more than a useful adjunct to current myocardial perfusion imaging studies. A strength of metabolic imaging is in the assessment of regional myocardial differences in metabolic activity, probing for 1 substrate at a time. We hope that new and developing methods of cardiac imaging will lead to the earlier detection of heart disease and improve the management and quality of life for patients afflicted with ischemic and nonischemic heart muscle disorders.
\end{abstract}

Key Words: cardiology (basic/technical); molecular imaging; $\mathrm{PET} / \mathrm{MRI}$; cardiac substrate imaging; cardiac metabolic imaging; cardiac structural imaging

J Nucl Med 2010; 51:80S-87S

DOI: 10.2967/jnumed.109.068205

$\mathbf{T}$ he importance of intermediary metabolism to sustain the function of the heart has long been appreciated. For example, it was known early in the 1900s that oxidative metabolism of energy-providing substrates-fatty acids, carbohydrates, amino acids, and even adenine nucleotidesis essential for the pumping function of the heart (1). Only much more recently has it become possible to assess cardiac metabolism both noninvasively and dynamically. However, even the most sophisticated techniques can still assess only the proverbial tip of the iceberg (2).

Much progress has been made during the past half century in imaging the cardiovascular system. However, the needs for the early detection and management of most forms of heart disease are still not completely met. Quantitative methods that integrate cardiovascular physiology and metabolism should be able to meet this challenge. Recent advances in

Received Mar. 1, 2010; revision accepted Apr. 1, 2010.

For correspondence or reprints contact: Heinrich Taegtmeyer, Division of Cardiology, Department of Internal Medicine, University of Texas Medical School at Houston, 6431 Fannin, MSB 1.246, Houston, TX 77030.

E-mail: Heinrich.Taegtmeyer@uth.tmc.edu

COPYRIGHT @ 2010 by the Society of Nuclear Medicine, Inc. this field are both conceptual and technical. For example, in the stressed heart, metabolic remodeling precedes, triggers, and maintains functional and structural remodeling (3). At the same time, much has been learned about the biochemical derangements underlying metabolic and structural remodeling of the heart.

The bewildering network of pathways of intermediary metabolism is well documented in any textbook of biochemistry. For our purposes, the principles of cardiac metabolism can be more easily understood if approached from the following vantage point: in the myocardial cell, a series of enzyme-catalyzed reactions results in the efficient transfer of chemical energy into mechanical energy. Despite the biochemical complexity involved in this transaction, the overall activity of metabolic pathways (or flux through the pathways) can be readily traced throughout the entire heart. I will therefore begin our exploration into the subject of cardiac metabolism with a brief overview of the key substrates used for energy provision; then I will focus on the metabolic tracers that can be used to noninvasively view these reactions in vivo and methods to visualize them. The ultimate goals of this discussion are to emphasize the ability of isotopic tracers to detect the metabolic footprints of heart disease and to propose that cardiac metabolic imaging is more than a useful adjunct to current myocardial perfusion imaging studies. The goal is that metabolic imaging will lead to targeted, noninvasive information as a basis for interventions in the treatment of heart disease, including ischemia, hypertrophy, and heart failure.

\section{METABOLISM: A BOOK WITH MANY CHAPTERS}

Cardiac metabolism is a book with many chapters, all expounding on the principal theme of the dynamic state of energy transfer and the dynamic state of functional proteins that constitute the myocardium itself. The former describes intermediary metabolism, and the latter refers to the turnover of myocardial proteins, most of which are enzymes, contractile elements, receptors, or transporters.

Metabolic imaging uses the tools of radionuclide tracers or magnetic resonance to trace either the flux of energyproviding substrates or the steady-state concentrations of metabolites by noninvasive methods. Although there are noninvasive methods to assess receptor physiology, reliable 
methods for the noninvasive assessment of myocardial protein turnover are currently not available.

\section{TRANSFER OF ENERGY, THE PRIME MOVER OF METABOLISM}

As stated, the key function of intermediary metabolism is the regulated, controlled transfer of chemical energy to adenosine triphosphate (ATP) and, by implication, to contraction of the heart muscle (4). This is a complex process, the details of which were discovered over a period of many years, and includes 3 phases: pathway identification (up until the 1950s), pathway regulation (up until the 1990s), and quantification of pathway fluxes (until the present). Pathway identification dates back to the discovery of the first law of thermodynamics. In his experiments on the chemistry of muscle contraction, Helmholtz observed that a chemical transformation of the compounds within the muscle itself was necessary for muscular contraction (5). Within the cardiovascular system, the myocardium requires an uninterrupted supply of energy-providing substrates to support rhythmic contractions (6). It is the oxidative metabolism of energy-providing substrates that provides this energy, and the amount of energy used is controlled by the oxygen demands of the myocardium.

As an organ designed for continuous, rhythmic aerobic work under constantly changing environmental conditions, the heart uses a variety of oxidizable substrates for energy provision. Acute changes in myocardial energy demands are met by changes in flux through existing metabolic pathways $(3,7)$. In contrast, with chronic changes in its environment, the heart adapts to chronic conditions by changing the rates of synthesis and degradation of the enzyme proteins that constitute the catalysts of metabolic pathways (8). The bottom line is that through these complex and highly regulated mechanisms, the heart manages to maintain a balance of energy supply proportional to its needs.

Using a variety of available methods - such as nuclear magnetic resonance (NMR) spectroscopy, MRI, PET, and SPECT - for assessing metabolic activity of the heart, both investigators and physicians can metabolically identify heart muscle tissue that is reversibly dysfunctional compared with tissue that is irreversibly so. For this reason, the past decade has witnessed renewed interest in cardiac metabolism. For example, we have proposed that metabolic changes often antedate functional contractile changes, and that these changes can be traced by noninvasive imaging methods (3). Others have shown that in the human heart, glucose use is inversely proportional to fatty acid use by the heart (9), and that in the heart of obese women, increased myocardial oxygen consumption is associated with a decrease in efficiency (10). Another, already well-established, hypothesis is that metabolic activity correlates with the viability of stressed or injured myocardial tissue (8). The endpoint of both of these lines of reasoning is that noninvasive imaging techniques can be used to evaluate these metabolic changes to assess the health of the heart.

\section{METABOLIC CYCLES}

The greater the cardiac output, the higher the rate of substrate use to provide for the increase in oxygen demand. Increased rates of oxygen consumption are directly correlated with increased rates of coronary blood flow. An important principle is that myocardial energy metabolism is not reflected by the tissue content of ATP but rather by the rate of ATP turnover (11).

Irrespective of the kind of substrate, the most efficient forms of energy transfer move through a series of interconnected cycles (Fig. 1) that improve the efficiency of energy transfer. In this scheme, energy transfer begins with cycles (systemic circulation and perfusion) and ends with cycles (cross-bridges of the sarcomeres) $(4,12)$. The metabolic pathways inside the cell include several interconnected cycles, most notably the Krebs cycle, the proton gradient in the respiratory chain, and the ATP cycle. Metabolic cycles transform substrates into usable energy via a series of enzyme-catalyzed reactions. As Figure 1 shows, tracers for perfusion $\left({ }^{201} \mathrm{Tl},{ }^{82} \mathrm{Rb},{ }^{13} \mathrm{NH}_{3}\right)$, Krebs cycle activity $\left({ }^{11} \mathrm{C}\right.$ acetate), proton production $\left({ }^{11} \mathrm{H}\right)$, and high-energy phosphates $\left({ }^{31} \mathrm{P}\right)$ are either intermediary metabolites or substrates for metabolic activity. Metabolic imaging cannot image the cycles themselves, but it can assess flux through the overall pathway of cycles instead.

\section{OPPORTUNITIES FOR IMAGING METABOLISM}

The heart is a metabolic omnivore-that is, it feeds on a variety of substrates (13). Its metabolic machinery has the capacity to produce ATP from many different substrates, chiefly from fatty acids and glucose (6). The breakdown of substrates can be divided into several stages (Fig. 2). Each of

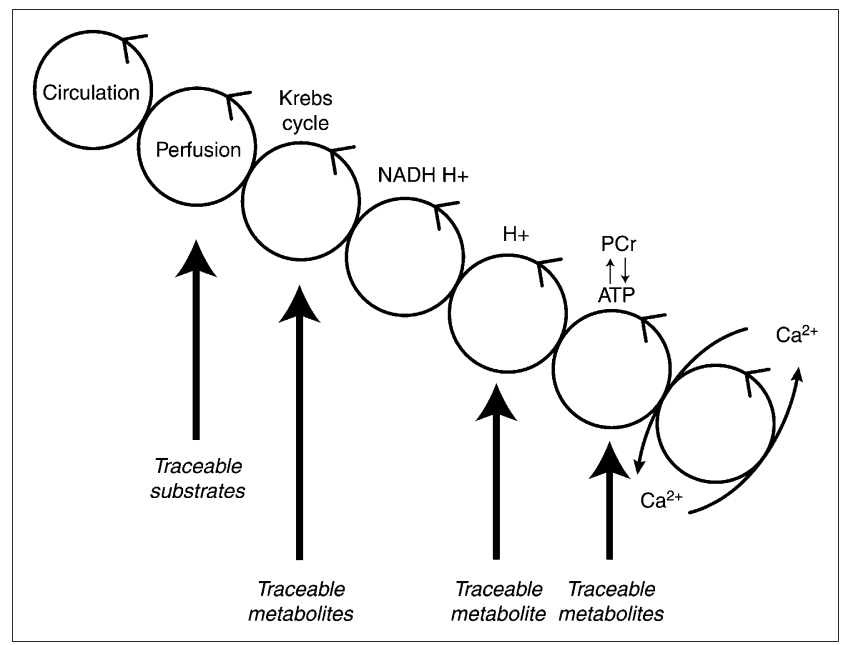

FIGURE 1. Transfer of energy from coronary circulation to contractile elements (cross-bridges) moves through series of moiety-conserved cycles. Substrates and metabolites can be traced by noninvasive methods. $\mathrm{NADH}=$ reduced nicotinamide adenine dinucleotide; $\mathrm{PCr}=$ phosphocreatine. 


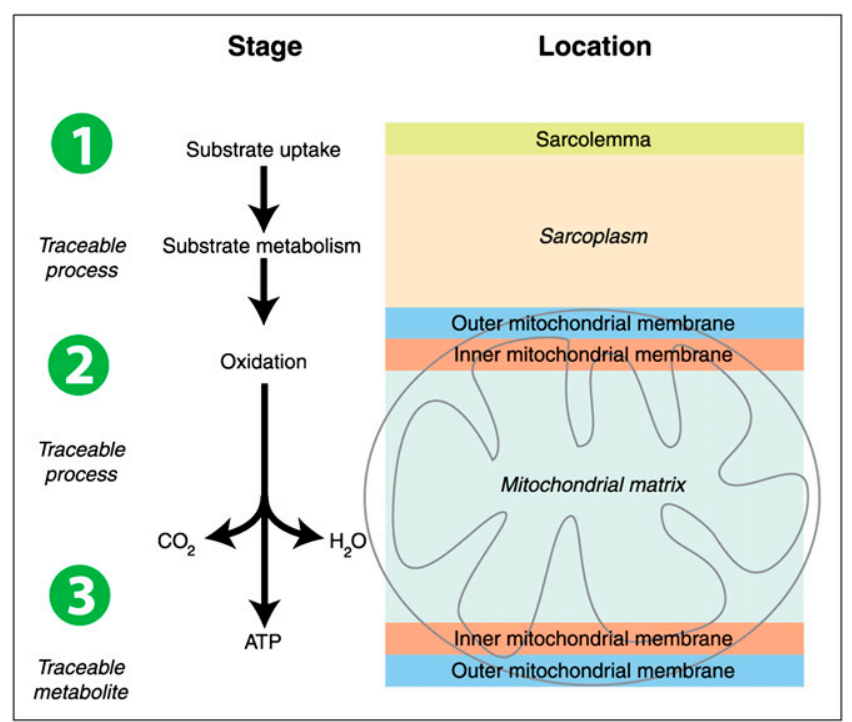

FIGURE 2. Substrate metabolism in heart can be divided into substrate uptake and metabolism (1), oxidation (2), and ATP production (3). Each state can be traced.

the stages can be selectively probed with positron-labeled tracers (substrates, acetate, and oxygen) or with stable isotopes $\left({ }^{13} \mathrm{C}\right.$ and $\left.{ }^{31} \mathrm{P}\right)$. The first stage of this process is the uptake of substrate by the cell for metabolism in a pathway, the end products of which include acetyl-coenzyme A (acetyl-CoA). The second stage consists of oxidation of acetyl-CoA and the subsequent generation of reducing equivalents and $\mathrm{CO}_{2}$ in the Krebs cycle. The third stage consists of the reducing equivalents generated in stage II undergoing a reaction with molecular oxygen in the respiratory chain, in which electron transfer is coupled to rephosphorylation of adenosine diphosphate to ATP. Table 1 lists several positron-labeled tracers and tracer analogs available to clinicians and investigators for the assessment of the 3 stages of energy substrate metabolism in the heart (or any other organ in the living mammalian organism). As Figure 3 shows, there are tracers to assess myocardial perfusion, to assess substrate uptake and retention (e.g., the glucose tracer analog ${ }^{18} \mathrm{~F}$-FDG or the long-chain fatty acid tracer analog), to assess flux of entire metabolic pathways, and to assess citric acid cycle flux. Metabolic activity in the heart is highly regulated and strongly influenced by the physiologic environment. All these factors affect tracer activity in vivo. The following paragraphs illustrate this point by comparing mechanisms of metabolic regulation unraveled ex vivo (through perfusion experiments) or in vivo (through transgenesis) with findings obtained with metabolic imaging techniques (mostly PET) in humans or animal models of disease. The main point is that, for the most part, it is not difficult to translate the findings from the laboratory to the human heart and vice versa. Some of the principles of substrate metabolism by the heart will now be discussed in detail.
Fatty Acid Metabolism and Substrate Interaction

In the postprandial state and under resting conditions, long-chain fatty acids are the main fuel source for the heart (14). Fatty acids suppress glucose oxidation at the level of the enzyme pyruvate dehydrogenase $(15,16)$. Transcriptionally, long-chain fatty acid oxidation is regulated by the peroxisome proliferator-activated receptor- $\alpha$, a nuclear receptor that binds to the peroxisome proliferator response element to upregulate the transcription and translation of genes for all the enzymes involved in the $\beta$-oxidation of fatty acids (17). However, the main orchestrator of this complex is the peroxisome proliferator-activated receptor- $\gamma$ coactivator PGC1 $\alpha(18,19)$. The discovery of the PGC-1 family of coactivators (20) led to the identification of PGC1 $\alpha$ as an inducer of mitochondrial biogenesis and, consequently, to tightly coupled respiration and high rates of ATP production in the heart (21). The critical role of PGC1 $\alpha$ in the physiologic control of myocardial energy substrate metabolism has recently been well reviewed (22).

However, the heart also uses a storage system of endogenous substrates (glycogen and triglycerides) to buffer changes in the dietary or hemodynamic state $(23,24)$. For example, with an acute increase in workload of the isolated working rat heart, there is a resulting acute increase in myocardial oxygen consumption and $\mathrm{CO}_{2}$ production (25). During this process, the heart oxidizes carbohydrates to meet the increased energy demands for contraction. Although long-chain fatty acids are the predominant fuel for energy provision for the mammalian heart in the normal state, carbohydrates are the fuel for the fetal heart (26) and for the adult heart in a state of exercise or stress (27). In the stressed heart in vivo, the efficiency of glucose as substrate exceeds the efficiency of fatty acids as substrate by as much as $40 \%$ (28). This metabolic flexibility is an inherent property of the normal heart, and the relative predominance of a fuel for respiration depends on its arterial substrate concentration and on hormonal influences, workload, and oxygen supply. Simply put, it seems that for a given environment, the heart oxidizes the most efficient substrate (28).

Although plasma fatty acid and triglyceride levels vary depending on the dietary state of the whole organism, fluctuations in plasma glucose levels are relatively minor and are tightly controlled by insulin. Under resting conditions, glucose contributes about $30 \%$ of the fuel for respiration to the heart $(6,29,30)$, mostly through the generation of acetyl-CoA. However, there is also carboxylation of pyruvate, and pyruvate derived from glucose serves as an anaplerotic substrate for the Krebs cycle (31). Anaplerosis, which means "filling up" of cycle intermediates, is a prerequisite for normal cycle flux $(32,33)$ and essential for the initiation of fatty acid oxidation in the heart (34).

In the normal, nondiabetic mammalian organism, glucose levels in the blood are tightly regulated at approximately $5 \mathrm{mM}$ (or $90 \mathrm{mg} / \mathrm{dL}$ ). When the normal heart is stressed, it oxidizes first glycogen, then glucose and lactate (35); thus, with exercise and the subsequent depletion of 


\section{TABLE 1. Tracers, Tracer Analogs, and Metabolic Processes They Identify}

Tracers and analogs

Metabolic process

Tracers

${ }^{11} \mathrm{C}$-glucose

${ }^{11} \mathrm{C}$-palmitate

${ }^{11} \mathrm{C}$ - $\beta$-methyl heptadecanoic acid

${ }^{11} \mathrm{C}$-lactate

${ }^{11} \mathrm{C}$-acetate

${ }^{15} \mathrm{O}-\mathrm{O}_{2}$

$\left[\mathrm{N}\right.$-methyl- $\left.{ }^{11} \mathrm{C}\right] \alpha$ methylaminoisobutyric acid

${ }^{11} \mathrm{C}$-glutamate

${ }^{11} \mathrm{C}$-aspartate

${ }^{13} \mathrm{~N}$-glutamate

${ }^{13} \mathrm{~N}$-ammonia

${ }^{38} \mathrm{~K}$

${ }^{81} \mathrm{Rb}$ or ${ }^{82} \mathrm{Rb}$

${ }^{52} \mathrm{Mn}$

${ }^{15} \mathrm{O}-\mathrm{H}_{2} \mathrm{O}$

Tracer analogs

${ }^{18} \mathrm{~F}-\mathrm{FDG}$

${ }^{18} \mathrm{~F}$-fluoro-6-thia-heptadecanoic acid

123/-iodophenyl-pentadecanoic acid

${ }^{18}$ F-fluoro-4-thia-palmitate

${ }^{18} \mathrm{~F}$-fluoro-3,4-methylene-heptadecanoic acid

${ }^{123}$ - $\beta$-methyl- $p$-iodophenyl-pentadecanoic acid

123I-metaiodobenzylguanidine

(S)- ${ }^{18} \mathrm{~F}$-fluoroethylcarbozol

${ }^{64} \mathrm{Cu}$-ATSM [diacetyl-bis(N4-methylthiosemicarbazone)]

${ }^{18} \mathrm{~F}$-fluoromisonidazole
Glucose metabolism (uptake, glycolysis, glycogen synthesis, oxidation)

Long-chain and straight-chain fatty acid uptake, triglyceride synthesis, and fatty acid oxidation

Long-chain and branched-chain fatty acid uptake

Lactate oxidation

Acetate oxidation, oxygen consumption

Amino acid oxidation

Myocardial perfusion (metabolic trapping)

Myocardial perfusion (ion pump)

Myocardial perfusion (diffusion)

Glucose uptake (transport and phosphorylation)

Long-chain and straight-chain fatty acid uptake

Adrenergic receptor metabolism

Hypoxia glycogen stores, blood lactate levels rise and blood lactate replaces all other substrates as fuel for the heart. Furthermore, element isotopic tracer studies have shown that the normal human heart simultaneously produces and oxidizes lactate, as well as using glucose to form glycogen when the body is in a fasted, resting state (31). In excellent tracer kinetic studies of the human heart, it has been estimated that half the amount of exogenous glucose is shunted first into glycogen before it is oxidized (36). Glucose and lactate extraction by the heart rises with an increase in workload, even in the presence of competing substrates both in vivo (37) and ex vivo (25). This observation is of interest because pyruvate is the common metabolic product of glucose, glycogen, and lactate metabolism, and because pyruvate competes effectively for the fuel of respiration. The likely mechanism involves inhibition of carnitine palmityl transferase I (CPTI) by malonyl-CoA $(25,38,39)$. With sustained inotropic stimulation of the heart, however, rates of fatty acid oxidation increase, most likely by activation of the enzyme malonyl-CoA decarboxylase and de-inhibition of CPTI (40).

\section{Imaging Glucose and Fatty Acid Metabolism}

Tracers for the assessment of glucose metabolism in the intact heart include ${ }^{11} \mathrm{C}$-glucose and the glucose tracer analog ${ }^{18} \mathrm{~F}$-FDG (Fig. 4). ${ }^{18} \mathrm{~F}$-FDG is phosphorylated by hexokinase to ${ }^{18} \mathrm{~F}$-FDG 6-phosphate but is not metabolized further in the glycolytic pathway and is thus trapped in the myocardium. Increased uptake of glucose, and therefore ${ }^{18} \mathrm{~F}-\mathrm{FDG}$, by ischemic myocardium occurs in response to ischemic ATP depletion, with the aim of maintaining cellular viability (41).

The tracer analog technique to assess glucose transport and phosphorylation has been validated in the isolated

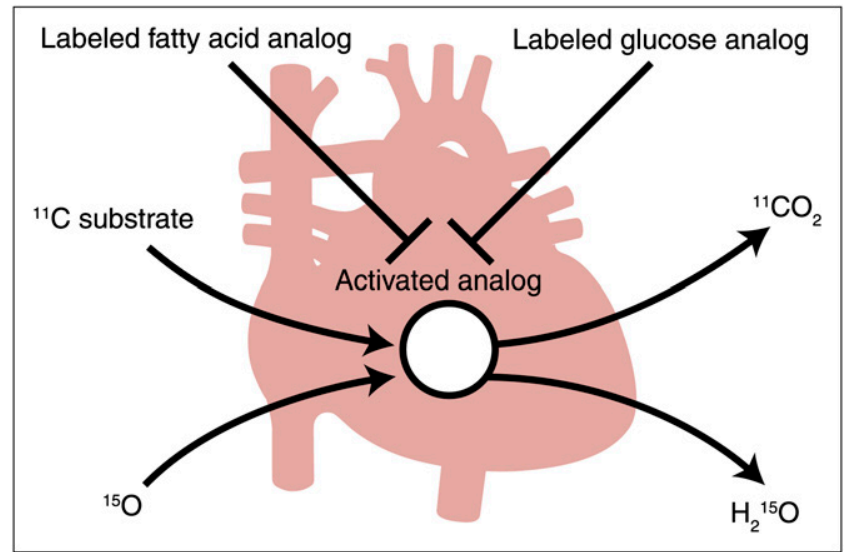

FIGURE 3. Positron-labeled tracer analogs for either fatty acids or glucose are transported into heart muscle cell and retained, whereas positron-labeled tracer substrates $\left({ }^{11} \mathrm{C}\right.$ compounds and ${ }^{15} \mathrm{O}_{2}$ ) are taken up, metabolized, and released (as either ${ }^{11} \mathrm{CO}_{2}$ or $\mathrm{H}_{2}{ }^{15} \mathrm{O}$ ). 


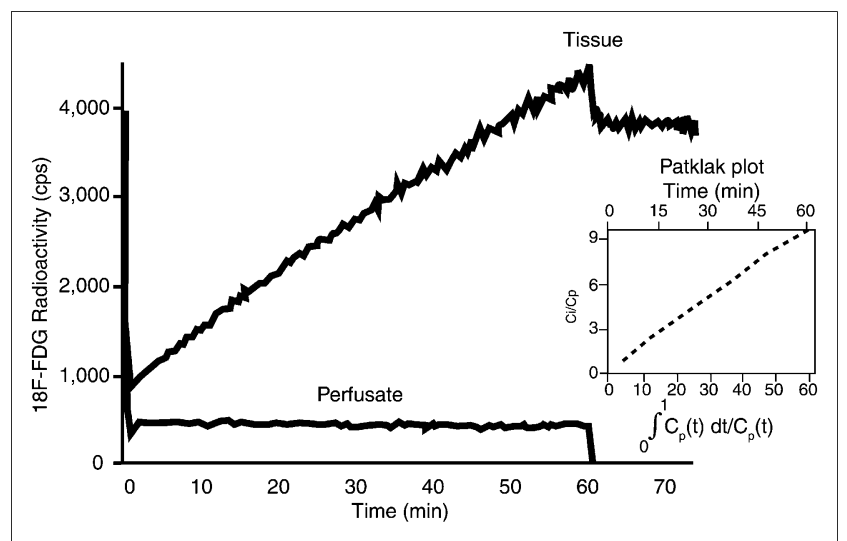

FIGURE 4. Progressive accumulation of glucose tracer analog ${ }^{18} \mathrm{~F}-\mathrm{FDG}$ by isolated working rat heart perfused with Krebs-Henseleit bicarbonate saline containing glucose $(5$ $\mathrm{mM}$ ) as substrate. Input function (radioactivity in perfusate) was stable (lower curve). At $60 \mathrm{~min}$, perfusate was switched to same saline without tracer analog (lower curve). Tissue retention of tracer analog was stable (upper curve). Cardiac work was same throughout experiment. $\mathrm{Ci}=$ intracellular concentration; $\mathrm{Cp}=$ perfusate concentration; $\mathrm{dt}=$ change in time; $\mathrm{t}=$ time. (Adapted from (42).)

working rat heart, in which ${ }^{18} \mathrm{~F}-\mathrm{FDG}$ accumulates in a linear fashion and is retained when the perfusate is switched to tracer-free medium (right side of diagram in Fig. 4) (42). Quantification of myocardial glucose uptake requires a stable tracer-tracee ratio and a stable "lumped constant," which is a correction factor in the tracer kinetic model for the assessment of glucose uptake and phosphorylation by 2deoxyglucose accounting for differences between ${ }^{18} \mathrm{~F}$-FDG and natural glucose. It consists of 6 separate constants and was first developed for brain studies (43). Although it is assumed that the lumped constant is constant in the heart in situ, the lumped constant changes under non-steady-state conditions-for example, with the administration of insulin (44) and with reperfusion after ischemia (45); we have proposed a tracer kinetic model that takes into account changes of the lumped constant under non-steady-state conditions (46). Similar considerations involving a lumped constant and its variability also apply to tracer analogs of fatty acids such as ${ }^{18} \mathrm{~F}$-labeled 4-thia palmitate and $15-{ }^{18} \mathrm{~F}$ fluoro-3-oxapentadecanoate, which have been used to assess derangements of myocardial fatty acid metabolism in heart failure (47). Rates of glucose metabolism can be directly assessed with the tracer ${ }^{11} \mathrm{C}$-glucose, which provides accurate quantification of myocardial glucose use in vivo. This approach is much more demanding for the investigator because it requires blood sampling with metabolite analysis. Few laboratories are able to perform this protocol (48). ${ }^{18} \mathrm{~F}$-FDG therefore remains the most popular method for the assessment of myocardial glucose metabolism.

${ }^{18} \mathrm{~F}-\mathrm{FDG}$ uptake by the heart depends on the glucose concentration in the plasma, the rate of glucose delivery to the heart, and the rate of glucose use by the heart muscle cells. An elevated plasma glucose concentration will decrease the fractional extraction of ${ }^{18} \mathrm{~F}-\mathrm{FDG}$ and thus decrease the quality of the myocardial ${ }^{18} \mathrm{~F}$-FDG uptake image $(49,50)$. In addition, studies have shown that certain conditions can enhance ${ }^{18} \mathrm{~F}-\mathrm{FDG}$ uptake by increasing regional glucose use. Such factors include an increase in myocardial work, an increase in catecholamines, or a decrease in plasma levels of free fatty acids $(4,51)$. However, the most important reason for an increase in regional myocardial glucose uptake is reprogramming of hibernating myocardium to the fetal gene program (52-55). There have been many attempts to standardize the metabolic environment for myocardial ${ }^{18} \mathrm{~F}-\mathrm{FDG}$ imaging with PET. These include oral glucose loading (50-75 g) to stimulate insulin secretion by the $\beta$-cells. Studies have shown that oral glucose loading has a positive effect on image quality, with a more homogeneously distributed tracer analog in comparison with a fasting state (56). However, as mentioned previously, an increase in glucose concentration can lower the fractional use of ${ }^{18} \mathrm{~F}-\mathrm{FDG}$ and decrease the quality of the image, thus counteracting the positive effect of increased regional glucose use. Patients with coronary artery disease, especially those with underlying diabetes, will still have poor image quality with oral glucose loading (56). A little-known alternative to ${ }^{18} \mathrm{~F}$-FDG imaging in myocardial ischemia is enhanced ${ }^{13} \mathrm{~N}$-glutamate uptake (57). However, this method awaits further development.

The euglycemic hyperinsulinemic clamp is an approach that mimics the postabsorptive steady state and has thus become an alternative approach to oral glucose loading for enhancing glucose and ${ }^{18} \mathrm{~F}$-FDG use $(49,58)$. Even in patients with diabetes, insulin clamping has yielded myocardial molecular images of high diagnostic value (59). However, similar degrees of glucose uptake variability exist between oral glucose loading and insulin clamping, most likely secondary to the variability in free fatty acid and lactate levels (59). A relatively easy approach to reduce plasma free fatty acid concentrations and improve image quality is the oral administration of nicotinic acid, which inhibits peripheral lipolysis $(50,60)$.

To conclude this section, both the complexity and the magnitude of myocardial energy metabolism can be overwhelming if not approached systematically beginning at the cellular level. Mitochondrial metabolism provides the human heart with more than $5 \mathrm{~kg}$ of ATP per day (51). In addition to the network of energy transfer of the heart, recent studies have stressed the diverse functions of cardiac metabolism. Besides providing energy for muscle contraction, the metabolism of substrates also provides signals for growth, gene expression, apoptosis, and programmed cell survival. Although the role of metabolic signaling in myocardial stunning and hibernation has already been recognized (61), its role in cardiac growth and gene expression has not yet been systematically addressed. Here metabolic imaging may be in a unique position to shed light 
on some of the unanswered questions regarding both shortand long-term adaptation of the heart to various forms to stress (62).

\section{Imaging Metabolic Adaptation and Maladaptation of the Heart}

The heart adapts or does not adapt in response to changes in its physiologic environment (Fig. 5). Here the physiologic environment of the heart includes the hemodynamic, the metabolic, and the circulatory environments. Like Opie and Sack, who introduced the concept of metabolic plasticity (63), we have argued that changes in the environment of the heart give rise to specific metabolic signals affecting cardiac structure and function (64).

Perhaps the most dramatic example of chronic metabolic adaptation is hibernating myocardium. Hibernating myocardium is a chronically dysfunctional myocardium and is most likely the result of extensive cellular reprogramming due to repetitive episodes of ischemia or chronic hypoperfusion (65). Functionally hibernating myocardium is characterized by an improvement of contractile function with reperfusion or inotropic stimulation. Metabolically, hibernating myocardium is characterized by a switch from fat to glucose metabolism, accompanied by reactivation of the fetal gene program (66). Because glucose transport and phosphorylation are readily traced by the uptake and retention of ${ }^{18} \mathrm{~F}-\mathrm{FDG}$, hibernating myocardium is readily detected by enhanced glucose uptake and glycogen accumulation in the same regions (67). Although rates of glucose oxidation are

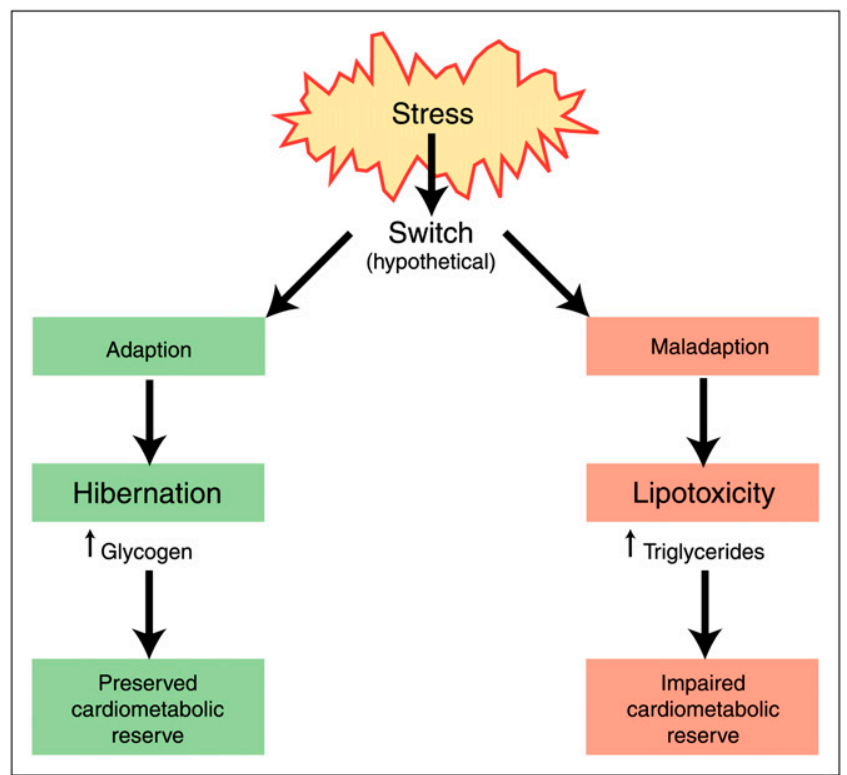

FIGURE 5. Adaptive and maladaptive stress responses of myocardium. Adaptive response of myocardial hibernation has distinctly different features from maladaptive response of myocardial lipotoxicity. Both processes can be traced by noninvasive methods. (Adapted from (64).) reduced, the glycogen content of hibernating myocardium is dramatically increased (68). A direct correlation exists between glycogen content and myocardial levels of ATP (69), and one may be tempted to speculate that improved energetics is the result of improved glycogen metabolism in hibernating myocardium. However, the true mechanism for viability remodeling of ischemic myocardium is likely to be much more complex, and good evidence exists for the activation of a gene expression program of cell survival (68). The similarities between the hibernating and the fetal myocardium suggest an innate mechanism of myocardial protection. In time, molecular imaging may shed more light on this process.

A fitting example for chronic metabolic maladaptation is the lipotoxic heart. Lipotoxicity, or glucolipotoxicity, is the result of severe metabolic dysregulation in the face of excess substrate supply and impaired substrate oxidation $(70,71)$. In contrast to hibernating myocardium, the metabolic changes are maladaptive and are reversible only with the restoration of a normal metabolic milieu (72). Consequences of dysregulated oxidative metabolism of glucose and fatty acids are the accumulation of glycosylated proteins, triglycerides, reactive oxygen species, diacylglycerol, and ceramide, among others (73). Dysregulated fatty acid metabolism provides a rich source of metabolic signals, some of which are regulators of gene expression by binding to specific transcription factors.

Failing human heart muscle has a high percentage of triglyceride accumulation. Triglyceride levels are highest in obese patients and in patients with type 2 diabetes mellitus. Triglycerides in cardiomyocytes, or ectopic fat, are considered markers rather than mediators of lipotoxicity (74). The advent of MRI is providing an opportunity to image intramyocardial triglycerides in vivo (75). The same group of investigators found that increased myocardial triglyceride content was accompanied by increased ventricular mass and decreased septal thickening (76). Good evidence also exists for ectopic triglyceride accumulation in the interventricular septum of patients with type 2 diabetes or the metabolic syndrome (77). Myocardial steatosis has been associated with impaired left ventricular function in patients with uncomplicated type 2 diabetes (78). Myocardial triglyceride accumulation can be reversed with either exercise or pharmacologic intervention.

Myocardial proton MR spectroscopy to study triglyceride content is a promising new tool to assess the effects of nutritional interventions on myocardial lipid metabolism in relation to heart function (79). The in vivo assessment of myocardial triglyceride content and turnover has already provided new insights into the pathophysiology of the heart in obesity and diabetes $(77,80)$.

\section{CONCLUSION}

Based on the principles of cardiac metabolism, I have reviewed the biochemical basis for the various imaging 
modalities available to track the footprints of normal and deranged metabolic activity in the heart. Akin to flow imaging with radionuclide tracers, a strength of metabolic imaging is in the assessment of regional myocardial differences in metabolic activity, probing for 1 substrate at a time. A strong case has been made for the utility of metabolic imaging in the detection of viable yet dysfunctional myocardium that could benefit from reperfusion. At the same time, we have still much to learn about the molecular basis of metabolic derangements in all forms of heart disease. The in vivo metabolic imaging of regenerative processes, including remodeling of the heart muscle through controlled protein synthesis and degradation, is still beyond the scope of current imaging modalities. However, it is our hope that new and developing methods of cardiac imaging will lead to the earlier detection of heart disease and improve the management and quality of life for patients afflicted with ischemic and nonischemic heart muscle disorders.

\section{ACKNOWLEDGMENTS}

I thank Romain Harmancey for critical comments, Khaled Khalaf for compiling Table 1, and Roxy A. Tate for her expert editorial assistance. Work in my laboratory is supported by the National Heart, Lung and Blood Institute and by the American Heart Association.

\section{REFERENCES}

1. Winterstein H. Ueber die Sauerstoffatmung des isolierten Saeugetierherzens. Z Allg Physiol. 1904;4:339-359.

2. Taegtmeyer H. Myocardial energetics: still only the tip of an iceberg. Heart Lung Circ. 2003;12:3-6.

3. Taegtmeyer H, Golfman L, Sharma S, Razeghi P, van Arsdall M. Linking gene expression to function: metabolic flexibility in the normal and diseased heart. Ann N Y Acad Sci. 2004;1015:202-213.

4. Taegtmeyer H. Energy metabolism of the heart: from basic concepts to clinical applications. Curr Probl Cardiol. 1994;19:59-113.

5. Holmes FL. Between Biology and Medicine: The Formation of Intermediary Metabolism. Berkeley, CA: University of California at Berkeley; 1992:114.

6. Taegtmeyer H, Hems R, Krebs HA. Utilization of energy-providing substrates in the isolated working rat heart. Biochem J. 1980;186:701-711.

7. Katz AM. Molecular biology in cardiology, a paradigmatic shift. J Mol Cell Cardiol. 1988;20:355-366.

8. Taegtmeyer H. Fueling the heart: multiple roles for cardiac metabolism. In: Willerson JT, Cohn JN, Wellens HJJ, Holmes DR, eds. Cardiovascular Medicine. 3rd ed. London, U.K.: Springer-Verlag; 2007:1157-1169.

9. Herrero P, Peterson LR, McGill JB, et al. Increased myocardial fatty acid metabolism in patients with type 1 diabetes mellitus. J Am Coll Cardiol. 2006; 47:598-604.

10. Peterson LR, Herrero P, Schechtman KB, et al. Effect of obesity and insulin resistance on myocardial substrate metabolism and efficiency in young women. Circulation. 2004;109:2191-2196.

11. Balaban RS. Cardiac energy metabolism homeostasis: role of cytosolic calcium. J Mol Cell Cardiol. 2002;34:1259-1271.

12. Baldwin JE, Krebs HA. The evolution of metabolic cycles. Nature. 1981;291: 381-382.

13. Taegtmeyer H. Carbohydrate interconversions and energy production. Circulation. 1985;72:1-8.

14. Bing RJ, Siegel A, Ungar I, Gilbert M. Metabolism of the human heart. II. Studies on fat, ketone and amino acid metabolism. Am J Med. 1954;16:504-515.

15. Randle PJ, Garland PB, Hales CN, Newsholme EA. The glucose fatty-acid cycle: its role in insulin sensitivity and the metabolic disturbances of diabetes mellitus. Lancet. 1963;1:785-789.
16. Hue L, Taegtmeyer H. The Randle cycle revisited: a new head for an old hat. Am J Physiol Endocrinol Metab. 2009;297:E578-E591.

17. van Bilsen M, Van der Vusse GJ, Reneman RS. Transcriptional regulation of metabolic processes: implications for cardiac metabolism. Pflugers Arch. 1998; 437:2-14.

18. Arany Z, He H, Lin J, et al. Transcriptional coactivator PGC-1 alpha controls the energy state and contractile function of cardiac muscle. Cell Metab. 2005;1: 259-271.

19. Lehman JJ, Boudina S, Banke NH, et al. The transcriptional coactivator PGC-1 alpha is essential for maximal and efficient cardiac mitochondrial fatty acid oxidation and lipid homeostasis. Am J Physiol Heart Circ Physiol. 2008;295: H185-H196.

20. Puigserver P, Wu Z, Park CW, Graves R, Wright M, Spiegelman BM. A coldinducible coactivator of nuclear receptors linked to adaptive thermogenesis. Cell. 1998;92:829-839.

21. Lehman JJ, Barger PM, Kovacs A, Saffitz JE, Medeiros DM, Kelly DP. Peroxisome proliferator-activated receptor gamma coactivator-1 promotes cardiac mitochondrial biogenesis. J Clin Invest. 2000;106:847-856.

22. Finck BN, Kelly DP. Peroxisome proliferator-activated receptor gamma coactivator-1 (PGC-1) regulatory cascade in cardiac physiology and disease. Circulation. 2007;115:2540-2548.

23. Evans G. The glycogen content of the rat heart. J Physiol (Lond.). 1934;82: $468-480$.

24. Denton RM, Randle PJ. Concentrations of glycerides and phospholipids in rat heart and gastrocnemius muscles. Biochem J. 1967;104:416-422.

25. Goodwin GW, Taylor CS, Taegtmeyer H. Regulation of energy metabolism of the heart during acute increase in heart work. J Biol Chem. 1998;273:2953029539.

26. Fisher DJ, Heymann MA, Rudolph AM. Myocardial oxygen and carbohydrate consumption in fetal lambs in utero and in adult sheep. Am J Physiol. 1980;238: H399-H405.

27. Goodwin GW, Taegtmeyer H. Improved energy homeostasis of the heart in the metabolic state of exercise. Am J Physiol Heart Circ Physiol. 2000;279:H1490H1501.

28. Korvald C, Elvenes OP, Myrmel T. Myocardial substrate metabolism influences left ventricular energetics in vivo. Am J Physiol Heart Circ Physiol. 2000;278: H1345-H1351.

29. Bing RJ. The metabolism of the heart. Harvey Lect. 1954-55;50:27-70.

30. Stanley WC, Recchia FA, Lopaschuk GD. Myocardial substrate metabolism in the normal and failing heart. Physiol Rev. 2005;85:1093-1129.

31. Russell RR, Taegtmeyer H. Coenzyme A sequestration in rat hearts oxidizing ketone bodies. J Clin Invest. 1992;89:968-973.

32. Comte B, Vincent G, Bouchard B, Des Rosiers C. Probing the origin of acetyl$\mathrm{CoA}$ and oxaloacetate entering the citric acid cycle from the ${ }^{13} \mathrm{C}$ labeling of citrate released by perfused rat hearts. J Biol Chem. 1997;272:26117-26124.

33. Gibala MJ, Young ME, Taegtmeyer H. Anaplerosis of the citric acid cycle: role in energy metabolism of heart and skeletal muscle. Acta Physiol Scand. 2000; 168:657-665.

34. Tirosh R, Mishor T, Pinson A. Glucose is essential for the initiation of fatty acid oxidation in ATP-depleted cultured myocytes. Mol Cell Biochem. 1996;162: $159-163$.

35. Taegtmeyer H. The failing heart [letter]. N Engl J Med. 2007;356:2545-2546.

36. Wisneski JA, Gertz EW, Neese RA, Gruenke LD, Morris DL, Craig JC. Metabolic fate of extracted glucose in normal human myocardium. J Clin Invest. 1985;76:1819-1827.

37. Gertz EW, Wisneski JA, Stanley WC, Neese RA. Myocardial substrate utilization during exercise in humans. J Clin Invest. 1988;82:2017-2025.

38. McGarry JD, Mills SE, Long CS, Foster DW. Observations on the affinity for carnitine and malonyl-CoA sensitivity of carnitine palmitoyl transferase $I$ in animal and human tissues: demonstration of the presence of malonyl-CoA in non-hepatic tissues of the rat. Biochem J. 1983;214:21-28.

39. Ussher JR, Lopaschuk GD. The malonyl CoA axis as a potential target for treating ischaemic heart disease. Cardiovasc Res. 2008;79:259-268.

40. Goodwin GW, Taegtmeyer H. Regulation of fatty acid oxidation of the heart by MCD and ACC during contractile stimulation. Am J Physiol. 1999;277:E772E777.

41. Chen TM, Goodwin GW, Guthrie PH, Taegtmeyer H. Effects of insulin on glucose uptake by rat hearts during and after coronary flow reduction. Am J Physiol. 1997;273:H2170-H2177.

42. Nguyen VT, Mossberg KA, Tewson TJ, et al. Temporal analysis of myocardial glucose metabolism by 2-[18 F]fluoro-2-deoxy-D-glucose. Am J Physiol. 1990; 259:H1022-H1031.

43. Sokoloff L, Reivich M, Kennedy C, et al. The $\left[{ }^{14} \mathrm{C}\right]$ deoxyglucose method for the measurement of local cerebral glucose utilization: theory, procedure, and normal 
values in the conscious and anesthetized albino rat. J Neurochem. 1977;28: 897-916.

44. Hariharan R, Bray M, Ganim R, Doenst T, Goodwin GW, Taegtmeyer H. Fundamental limitations of $\left[{ }^{18} \mathrm{~F}\right] 2$-deoxy-2-fluoro-D-glucose for assessing myocardial glucose uptake. Circulation. 1995;91:2435-2444.

45. Doenst T, Taegtmeyer H. Profound underestimation of glucose uptake by $\left[{ }^{18} \mathrm{~F}\right] 2-$ deoxy-2-fluoroglucose in reperfused rat heart muscle. Circulation. 1998;97: 2454-2462.

46. Bøtker HE, Goodwin GW, Holden JE, Doenst T, Gjedde A, Taegtmeyer H. Myocardial glucose uptake measured with fluorodeoxyglucose: a proposed method to account for variable lumped constants. J Nucl Med. 1999;40:1186-1196.

47. DeGrado TR, Wang S, Holden JE, Nickles RJ, Taylor M, Stone CK. Synthesis and preliminary evaluation of ${ }^{18} \mathrm{~F}$-labeled 4-thia palmitate as a PET tracer of myocardial fatty acid oxidation. Nucl Med Biol. 2000;27:221-231.

48. Dence CS, Herrero P, Schwarz SW, Mach RH, Gropler RJ, Welch MJ. Imaging myocardium enzymatic pathways with carbon-11 radiotracers. Methods Enzymol. 2004;385:286-315.

49. Knuuti MJ, Nuutila P, Ruotsalainen U, et al. Euglycemic hyperinsulinemic clamp and oral glucose load in stimulating myocardial glucose utilization during positron-emission tomography. J Nucl Med. 1992;33:1255-1262.

50. Knuuti MJ, Yki-Jarvinen H, Voipio-Pulkki LM, et al. Enhancement of myocardial [fluorine-18]fluorodeoxyglucose uptake by a nicotinic acid derivative. J Nucl Med. 1994;35:989-998.

51. Opie L. Fuels: aerobic and anaerobic metabolism. In: The Heart: Physiology, from Cell to Circulation. Philadelphia, PA: Lippincott Raven; 1998:295.

52. Depre C, Vanoverschelde JL, Melin JA, et al. Structural and metabolic correlates of the reversibility of chronic left ventricular ischemic dysfunction in humans. Am J Physiol. 1995;268:H1265-H1275.

53. Vanoverschelde JL, Wijns W, Borgers M, et al. Chronic myocardial hibernation in humans: from bedside to bench. Circulation. 1997;95:1961-1971.

54. Camici PG, Wijns W, Borgers M, et al. Pathophysiological mechanisms of chronic reversible left ventricular dysfunction due to coronary artery disease (hibernating myocardium). Circulation. 1997;96:3205-3214.

55. Luisi AJ Jr, Suzuki G, Dekemp R, et al. Regional ${ }^{11} \mathrm{C}$-hydroxyephedrine retention in hibernating myocardium: chronic inhomogeneity of sympathetic innervation in the absence of infarction. J Nucl Med. 2005;46:1368-1374.

56. Berry JJ, Baker JA, Pieper KS, Hanson MW, Hoffman JM, Coleman RE. The effect of metabolic milieu on cardiac PET imaging using fluorine-18-deoxyglucose and nitrogen-13-ammonia in normal volunteers. J Nucl Med. 1991;32:1518-1525.

57. Zimmermann R, Tillmans H, Knopp WH. Regional myocardial ${ }^{13} \mathrm{~N}$-glutamate uptake in patients with coronary artery disease. J Am Coll Cardiol. 1988;11:549-556.

58. DeFronzo RA, Tobin JD, Andres R. Glucose clamp technique: a method for quantifying insulin secretion and resistance. Am J Physiol. 1979;237:E214-E223.

59. Knuuti J. PET imaging in the heart and skeletal muscle: an overview. In: Gropler RJ, Glover DK, Sinusas AJ, Taegtmeyer H, eds. Cardiovascular Molecular Imaging. New York, NY: Informa Healthcare USA, Inc.; 2007:319-324.

60. Stone CK, Holden JE, Stanley W, Perlman SB. Effect of nicotinic acid on exogenous myocardial glucose utilization. J Nucl Med. 1995;36:996-1002.

61. Depre C, Vatner SF. Mechanisms of cell survival in myocardial hibernation. Trends Cardiovasc Med. 2005;15:101-110.

62. Taegtmeyer H. Multiple roles of cardiac metabolism: new opportunities for imaging the physiology of the heart. In: Gropler RJ, Glover DK, Sinusas AJ,
Taegtmeyer H, eds. Cardiovascular Molecular Imaging. New York, NY: Informa Healthcare USA, Inc.; 2007:309-318.

63. Opie LH, Sack MN. Metabolic plasticity and the promotion of cardiac protection in ischemia and ischemic preconditioning. J Mol Cell Cardiol. 2002;34:10771089 .

64. Taegtmeyer H, Dilsizian V. Imaging myocardial metabolism and ischemic memory. Natl Clin Pract Cardiovasc Med. 2008;5(suppl 2):S42-S48.

65. van Rooij E, Marshall WS, Olson EN. Toward microRNA-based therapeutics for heart disease: the sense in antisense. Circ Res. 2008;103:919-928.

66. Rajabi M, Kassiotis C, Razeghi P, Taegtmeyer H. Return to the fetal gene program protects the stressed heart: a strong hypothesis. Heart Fail Rev. 2007;12: 331-343.

67. Mäki M, Luotolahti $M$, Nuutila $P$, et al. Glucose uptake in the chronically dysfunctional but viable myocardium. Circulation. 1996;93:1658-1666.

68. Depre C, Vanoverschelde JL, Gerber B, Borgers M, Melin JA, Dion R. Correlation of functional recovery with myocardial blood flow, glucose uptake, and morphologic features in patients with chronic left ventricular ischemic dysfunction undergoing coronary artery bypass grafting. J Thorac Cardiovasc Surg. 1997;113:371-378.

69. Depre C, Taegtmeyer H. Metabolic aspects of programmed cell survival and cell death in the heart. Cardiovasc Res. 2000;45:538-548.

70. Young ME, Guthrie PH, Razeghi P, et al. Impaired long-chain fatty acid oxidation and contractile dysfunction in the obese Zucker rat heart. Diabetes. 2002;51:2587-2595.

71. Sharma S, Adrogue JV, Golfman L, et al. Intramyocardial lipid accumulation in the failing human heart resembles the lipotoxic rat heart. FASEB J. 2004;18: 1692-1700.

72. Golfman LS, Wilson CR, Sharma S, et al. Activation of PPARgamma enhances myocardial glucose oxidation and improves contractile function in isolated working hearts of ZDF rats. Am J Physiol Endocrinol Metab. 2005;289:E328E336.

73. Harmancey R, Wilson CR, Taegtmeyer H. Adaptation and maladaptation of the heart in obesity. Hypertension. 2008;52:181-187.

74. Brookheart RT, Michel CI, Schaffer JE. As a matter of fat. Cell Metab. 2009;10: 9-12.

75. Szczepaniak LS, Babcock EE, Schick F, et al. Measurement of intracellular triglyceride stores by H spectroscopy: validation in vivo. Am J Physiol. 1999; 276:E977-E989.

76. Szczepaniak LS, Dobbins RL, Metzger GJ, et al. Myocardial triglycerides and systolic function in humans: in vivo evaluation by localized proton spectroscopy and cardiac imaging. Magn Reson Med. 2003;49:417-423.

77. McGavock JM, Lingvay I, Zib I, et al. Cardiac steatosis in diabetes mellitus: a ${ }^{1} \mathrm{H}$-magnetic resonance spectroscopy study. Circulation. 2007;116:1170-1175.

78. Rijzewijk LJ, van der Meer RW, Smit JW, et al. Myocardial steatosis is an independent predictor of diastolic dysfunction in type 2 diabetes mellitus. $\mathrm{J} \mathrm{Am}$ Coll Cardiol. 2008;52:1793-1799.

79. Lamb HJ, Smit JW, van der Meer RW, et al. Metabolic MRI of myocardial and hepatic triglyceride content in response to nutritional interventions. Curr Opin Clin Nutr Metab Care. 2008;11:573-579.

80. Szczepaniak LS, Victor RG, Orci L, Unger RH. Forgotten but not gone: the rediscovery of fatty heart, the most common unrecognized disease in America. Circ Res. 2007;101:759-767. 